\title{
Demonstrator zur interdisziplinåren Bewertung von virtuellen Kraftwerken
}

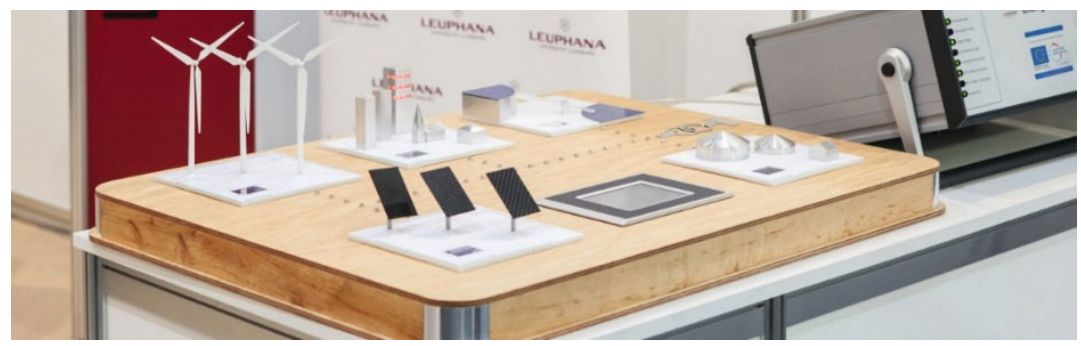

Das Kompetenztandem EnERgioN (Erneuerbare Energien in der Region Nord) ging der Frage nach, wie sich regionaler Strom aus erneuerbaren Energien besser in der Region speichern und verteilen lässt. Dafür prüfte das interdisziplinäre Forschungsteam Geschäftsansätze zu virtuellen Kraftwerken, die kleine, dezentrale und häufig von Privatpersonen betriebene Stromerzeuger zusammenschalten sollten. Die virtuellen Kraftwerke verknüpften Versorgungsunternehmen, Netzbetreiber und Konsumenten. Sie koordinierten Erzeugung, Speicherung und Verbrauch von Energie. Für die anschauliche Darstellung der Daten wurde ein Demonstrator entwickelt, der aus einer Simulationssoftware sowie aus Hardwarekomponenten zur Visualisierung der Ergebnisse bestand. Das Demonstrationsobjekt ermöglicht sowohl Fachpublikum als auch Laien einen anschaulichen Zugang zur Funktionalität eines virtuellen Kraftwerks.

Das System besteht aus 5 modularen Erzeugungs-, Speicher- und Verbrauchseinheiten, die über ein Kommunikationsnetzwerk miteinander verbunden sind. Das Modul, dass die Abbildung der zu untersuchenden Verbrauchseinheiten repräsentiert wird in Form einer abstrahierten Stadt dargestellt (siehe Abbildung 1). In ähnlicher Form dienen weitere abstrahierte Modelle der anschaulichen Darstellung einzelner Module des virtuellen Kraftwerks. Die Funktion als Testsystem wird durch eine eigenständige Stromversorgung sowie einen getrennten Signalübertragungspfad gewährleistet.

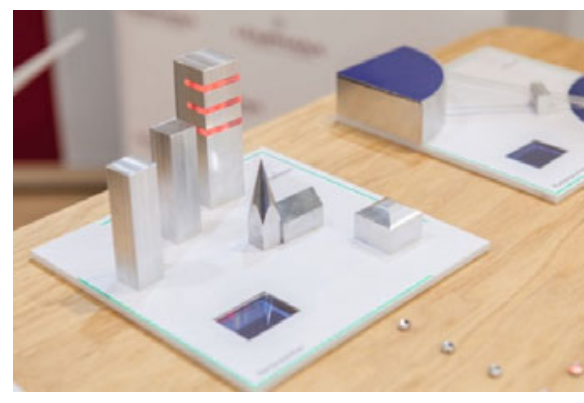

Abbildung 1: Moduls zur Darstellung der Verbraucher mittels einer virtuellen Stadt

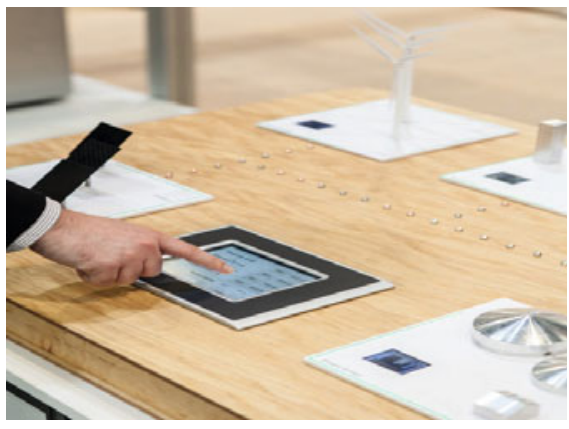

Abbildung 2: Operation Terminal zur zentralen Steuerung des virtuellen Kraftwerks
Das zentrale Steuerungs- und Überwachungssystem wurde ergänzend mit analogen sowie digitalen Steuerungsmodulen ausgestattet. Als weitere Steuerungseinheit wurde ein Operation Terminal integriert. Dieses ist in Abbildung 2 dargestellt. Es kann durch manuelle Bedienung an die jeweiligen Anforderungen individuell angepasst werden. Gleichzeitig ermöglicht es dem Benutzer, eine Rückmeldung über die vorgenommenen Handlungen und Veränderungen in Echtzeit zu bekommen. Die Steuerungen sind über Ethernet miteinander verbunden und führen einen ständigen Datenabgleich durch. 